\title{
30 years of IRMM-1027 reference materials for fissile material accountancy and control: development, production and characterisation
}

\author{
Rožle Jakopič ${ }^{1}$ (1) Kalman Toth $^{1}$. Jeroen Bauwens ${ }^{1} \cdot$ Renata Buják $^{2} \cdot$ Carmel Hennessy $^{1}$ - Frances Kehoe ${ }^{1}$. \\ Ulf Jacobsson ${ }^{1} \cdot$ Stephan Richter ${ }^{1}$. Yetunde Aregbe ${ }^{1}$
}

Received: 25 June 2021 / Accepted: 27 July 2021 / Published online: 15 August 2021

(c) The Author(s) 2021

\begin{abstract}
The IRMM-1027 Large-sized dried (LSD) spikes are certified reference materials applied to measure the uranium and plutonium content of dissolved fuel solutions using isotope dilution mass spectrometry. High quality starting metals of uranium and plutonium are dissolved to produce a stock solution, which is dispensed into individual vials and dried down. The present spikes are mixtures of typically $50 \mathrm{mg} 20 \%$ enriched $\mathrm{U}$ and $2 \mathrm{mg}$ enriched ${ }^{239} \mathrm{Pu}$ as dried nitrates, conditioned in an organic substance for stability. Each vial of an IRMM-1027 LSD spike comes with certified masses of uranium $\left({ }^{235} \mathrm{U}\right.$ and $\left.{ }^{238} \mathrm{U}\right)$ and

${ }^{239} \mathrm{Pu}$ and isotopic composition with associated uncertainty. This article will discuss major developments since the production of the first batch of LSD spikes and will reflect on the current preparation and certification approaches.
\end{abstract}

Keywords Large-sized dried (LSD) spike · Nuclear safeguards · Reprocessing · IDMS · CRM

\section{Introduction}

By signing the Treaty on the Non-Proliferation of Nuclear Weapons (NPT) and the EURATOM Treaty, all non-nuclear weapon states have to declare their fissile materials and comply with safeguards agreements $[1,2]$. Nuclear safeguards aims at the verification of the non-diversion of fissile material from its intended and declared peaceful use. This involves the quantitative determination of the uranium and plutonium contents at different stages of the fuel cycle, in particular in the dissolver solution of irradiated nuclear fuel at reprocessing plants. Safeguarding reprocessing plants poses a challenge to safeguards authorities because of their size, high material throughput and the requirement for a high level of detection probability of diverted material.

Rožle Jakopič

rozle.jakopic@ec.europa.eu

1 European Commission (EC), Joint Research Centre (JRC), Geel, Belgium

2 Department of Safeguards, Office of Safeguards Analytical Services, Environmental Sample Laboratory, International Atomic Energy Agency (IAEA), Seibersdorf, Austria
Isotope dilution mass spectrometry (IDMS) has been applied as a reliable analytical technique for accountancy measurements of uranium and plutonium contents in dissolved fuel when high accuracy is needed. A well-characterised spike is needed to achieve this high level of accuracy [3-6]. Such spikes are chosen preferentially with a high enrichment of an isotope that is not the main isotope of the element being measured. ${ }^{233} \mathrm{U}$ and ${ }^{242} \mathrm{Pu}$ (or even ${ }^{244} \mathrm{Pu}$ ) are commonly applied in IDMS analysis of nuclear materials when the concentration of the sample is suitable for handling in a radiochemical laboratory. However, due to the high radioactivity associated with the dissolver solution, dilution steps would be required to levels suitable for these spikes under typical glove-box conditions.

The use of much larger spikes applied directly to the dissolved nuclear material was proposed to obviate the need for a dilution of the dissolved fuel solution [7-13], even though this required the use of spike isotopes that are present in the sample to a greater or lesser extent $\left({ }^{235} \mathrm{U}\right.$ and $\left.{ }^{239} \mathrm{Pu}\right)$. These spikes contain milligram rather than microgram quantities of nuclear material and are in the dried form, the so-called large-sized dried (LSD) spikes. The main advantage of using LSD spikes is that the dilution of a sample of a dissolved nuclear fuel solution is no longer required, therefore simplifying the weighing process and reducing the overall 
uncertainty of the measured amounts of plutonium and uranium. Another advantage is to be able to use highly enriched and pure certified reference metals of ${ }^{235} \mathrm{U}$ and ${ }^{239} \mathrm{Pu}$ as starting materials. They are readily available in contrast to the more rare isotopes, ${ }^{233} \mathrm{U}$ and ${ }^{242} \mathrm{Pu}$, and so enable a spike production on a larger scale.

The Joint Research Centre (JRC) of the European Commission (EC) has been providing LSD spikes, the wellknown IRMM-1027 series, to the safeguards community since 1991 (i.e. IRMM-1027a batch). They have been applied at the on-site laboratories at the European reprocessing plants in La Hague and Sellafield and in industry worldwide. The present spikes contain about $50 \mathrm{mg} \mathrm{U}$ and $2 \mathrm{mg}$ $\mathrm{Pu}$ embedded in an organic matrix for stabilisation. The uranium component in the spike is enriched to just under $20 \%$ in ${ }^{235} \mathrm{U}$, the maximum enrichment at the time that could be delivered and handled at the reprocessing plants. The $\mathrm{Pu}$ component has a ${ }^{239} \mathrm{Pu}$ abundance of about $98 \%$. About 1000 units of IRMM-1027 LSD spikes are produced annually and certified in compliance with the ISO 17034 and ISO Guide $35[14,15]$. Spikes containing ${ }^{235} \mathrm{U}$ and ${ }^{239} \mathrm{Pu}$ have been successfully utilised in IDMS for safeguards inspections and in accountability measurements for operators at the reprocessing plants $[9,10,16-20]$. The extensive use of LSD spikes over the past years has shown that IDMS, applying these spikes routinely, provides accurate results with measurement uncertainties below the target values as required by the safeguards authorities. The international target values (ITV-2010) are uncertainties to be considered in judging the reliability of the measurement results of fissile materials, which are subject to safeguards verification. They represent the estimates of the state of the practice and should be achievable under the conditions normally encountered in a typical industrial laboratory or during actual inspections [21].

The present paper will summarise the main developments and improvements of the IRMM-1027 LSD spikes over the years, and look at the present production of the LSD spikes at the JRC Geel. The second part of the paper will focus on the characterisation methodology, by looking particularly at the homogeneity and stability aspects. Finally, some considerations for the future use of LSD spikes will be discussed.

\section{Historical developments}

The suggestion to use large-sized spikes was made more than 30 years ago. The intention was to remove a major source of uncertainty in the measurement of uranium and plutonium content in dissolved fuel by providing a spike for IDMS in which the concentrations of the $\mathrm{U}$ and Pu were high enough to eliminate the need for a preliminary large dilution of the highly active dissolved fuel solution. Dilution steps were difficult to carry out under normal working condition in hot-cells and were associated with potential sources of errors and risks of contaminating diluted samples.

The JRC Geel first investigated the development of large-sized spikes in metal form. They were produced by crucible-less induction melting techniques in an inert argon atmosphere $[22,23]$. The initial spikes were either binary or ternary U-Pu alloys but suffered from poor homogeneity of $\mathrm{Pu}$ in the alloy and solubility problems. In the following years, the metallic spikes were optimised by producing them as two separate metallic pieces, enriched uranium (19.5\% $\left.{ }^{235} \mathrm{U}\right)$ and a binary alloy of plutonium/gadolinium $(6 \% \mathrm{Pu})$. This improved the homogeneity of the Pu component, the weak point of the previous metallic spikes [7]. The metallic spikes had some advantages as they were simple to use when placed in a sealed vial and the dissolution in the fuel solution occurred readily. However, controlling the required degree of homogeneity of the plutonium metal alloy was difficult and a deterioration was found in the uranium metal over a period greater than 6 months, even when stored in an inert gas, from slow diffusion of air into the vial causing surface oxidation. Moreover, producing them in large quantities was technically difficult.

Over the years, the number of samples that needed to be analysed for safeguards purposes increased due to larger throughput of the reprocessing plants and as the requirements for more accurate accountability measurements with smaller uncertainties became stricter. Consequently, the demand for large-sized spikes also increased. This led to further developments aimed at more straightforward preparation procedures, and more homogeneous and accurately certified spikes [21, 24, 25].

In the mid-1980 s the development of metallic spikes was paralleled by the development of large-sized spikes, containing ${ }^{235} \mathrm{U}$ and ${ }^{239} \mathrm{Pu}$ as dried nitrate salts. The initial idea of these large-sized dried (LSD) spikes came from Masao Takahashi of the Nuclear Materials Control Centre (NMCC, Japan). The main advantage compared to metallic spikes was their simpler preparation from primary reference materials, while ensuring better homogeneity and traceability.

LSD spikes are prepared by dissolving highly enriched and pure uranium and plutonium reference metals in acid, dispensing weighed amounts of the solution into penicillin glass vials and drying. The starting materials of uranium and plutonium are mixed to arrive at a ratio of uranium to plutonium in the dried spike of approximately 25-30 to 1 . This ratio was selected after discussion with users of the spikes at the start of the LSD program, as being suitable for the measurement of the dissolved fuel $[13,26]$. At the beginning, uranium oxides were used as starting materials to prepare IRMM-1027 LSD spikes. To ensure the stoichiometry of $\mathrm{U}_{3} \mathrm{O}_{8}$, the oxides were ignited in an open furnace at $800^{\circ} \mathrm{C}$ for one hour and cooled in a desiccator prior to use. The 
uranium oxides were eventually replaced by uranium metals, with the preparation of the batch IRMM-1027f in 2002.

As the spikes were in a dried nitrate form, it was not easy to maintain their integrity over longer periods (e.g. 6 months). Dried nitrate material tends to crystallise over time and forms a loose, powder-like material in the vial with the obvious risk of spike loss upon use. In order to overcome this problem, an organic stabilising substance was applied on top of the dried nitrates to fix the spike material to the bottom of the glass vial, thus guaranteeing its stability during shipment.

The first few batches of IRMM-1027 LSD spikes were prepared with tetrahydrofuran (THF) as a protective organic coating $[11,13,27]$. THF yielded stable complexes with uranium and plutonium, but the preparation required a long drying procedure and the coating was not easily dissolved in warm nitric acid. In addition, THF is suspected to have carcinogenic effects [28].

Therefore, other organic substances based on cellulose esters were investigated [29]. Cellulose acetate butyrate (CAB) was chosen as an alternative for THF. In CAB, the hydrogen atoms of the hydroxyl groups are replaced by acetyl $\left(\mathrm{CH}_{3} \mathrm{CO}\right)$ and butyryl $\left(\mathrm{C}_{3} \mathrm{H}_{7} \mathrm{CO}\right)$ groups. Derivatives of $\mathrm{CAB}$ are characterised by a degree of substitution of the hydroxyl groups and have different properties depending on this degree. CAB has good characteristics such as solubility in many organic solvents, sufficient mechanical strength and good adherence to glass, minimal moisture uptake and a reasonable resistance to radiolysis. Moreover, it dissolves readily in warm nitric acid, leaving no residue and has no significant effect on the IDMS analysis.

The first chemical treatment of IRMM-1027 LSD spikes used CAB-17 with a 17-19\% butyryl content (17-19 g/100 g butyryl content). It provided a sufficient stability for a shortterm storage, but a longer shelf-life could not be guaranteed. Cracks and flaking of the organic covering material appeared, which could potentially lead to loss of the spike material when opening the vial. Further research was undertaken to tackle certain critical factors such as the conditioning of the glove-box air intake and stringent temperature tuning during evaporation and coating application. This optimised procedure improved the stability and durability of spikes to about two years.

Over the years, further investigation was necessary in order to meet customers` needs for spikes with a prolonged shelf life beyond two years. CABs with higher butyryl contents were studied to find the optimal polymer grade and a longer-lasting layer. The objective was to look for a butyryl degree that was strong enough to provide a robust layer, but at the same time would not influence the dissolution in nitric acid. The CAB-35 with 35-39\% butyryl content (35-39 g/100 g butyryl content) was chosen as the best candidate in terms of mechanical stability and resistance to radiation [30, 31]. It has been applied for the preparation of the IRMM-1027m series onwards [32-34].

A further improvement to the production of large-sized dried spikes was established in 2007 with the introduction of an automated system to replace the laborious manual dispensing of the $\mathrm{U} / \mathrm{Pu}$ mother solutions into individual penicillin vials [35]. It was designed to control all the movements inside the glove-box, from the identification of the vial with a barcode reader to dispensing and weighing the requested amount of the batch solution. This was a significant improvement because prior to this, skilled technicians had to dispense and weigh each individual spike manually to achieve the required accuracy. This operation took several weeks and, consequently evaporation corrections to the master batch solution were necessary. With the implementation of the automated system, the time to dispense and weigh the whole amount of the batch solution into vials has been reduced to 5 days. It also reduced considerably the exposure of personnel to ionising radiation.

The most recent improvement occurred in 2017 when JRC Geel and JRC Karlsruhe engaged in an exploratory research project to develop new types of coatings and spikes with different U/Pu ratios [36]. Among the tested materials, carboxymethyl cellulose (CMC) has shown promising results $[37,38]$. CMC is similar in structure to $\mathrm{CAB}$ but this cellulose derivative is functionalised with carboxymethyl groups. A protocol similar to the THF spike preparation is used and involves the use of a nitric acid solution. Upon drying, instead of a polymer film (CAB), a foam is produced in which the uranium and plutonium dried nitrates are homogeneously embedded. This foam dissolves almost instantly in hot nitric acid and has a high capacity for larger amounts of nuclear material. Furthermore, spikes prepared to date with CMC material remain stable for more than 4 years. The outcome of the exploratory research has been published in the open literature and the executive summary of the project is available on the EU Science Hub [36, 39, 40]. CMC coating has been implemented from the IRMM-1027t batch onwards [41, 42]. While developing the CMC matrix coating, the CAB-35 matrix was also improved by adding a plasticizer, dioctyl-phthalate (DOP) which made the embedding film less brittle and delayed cracking and flaking. For the IRMM1027t to the IRMM-1027v LSD spike batches, both CMC and $\mathrm{CAB}-35 / \mathrm{DOP}$ were used as stabilising matrix. An overview of IRMM-1027 LSD developments and improvements over the years is shown in Fig. 1.

\section{Present production of spikes}

The IRMM-1027 LSD series are prepared on an annual basis, as follows: plutonium metal (MP2, Commission d`Establissement des Methodes d`Analyse, France), 


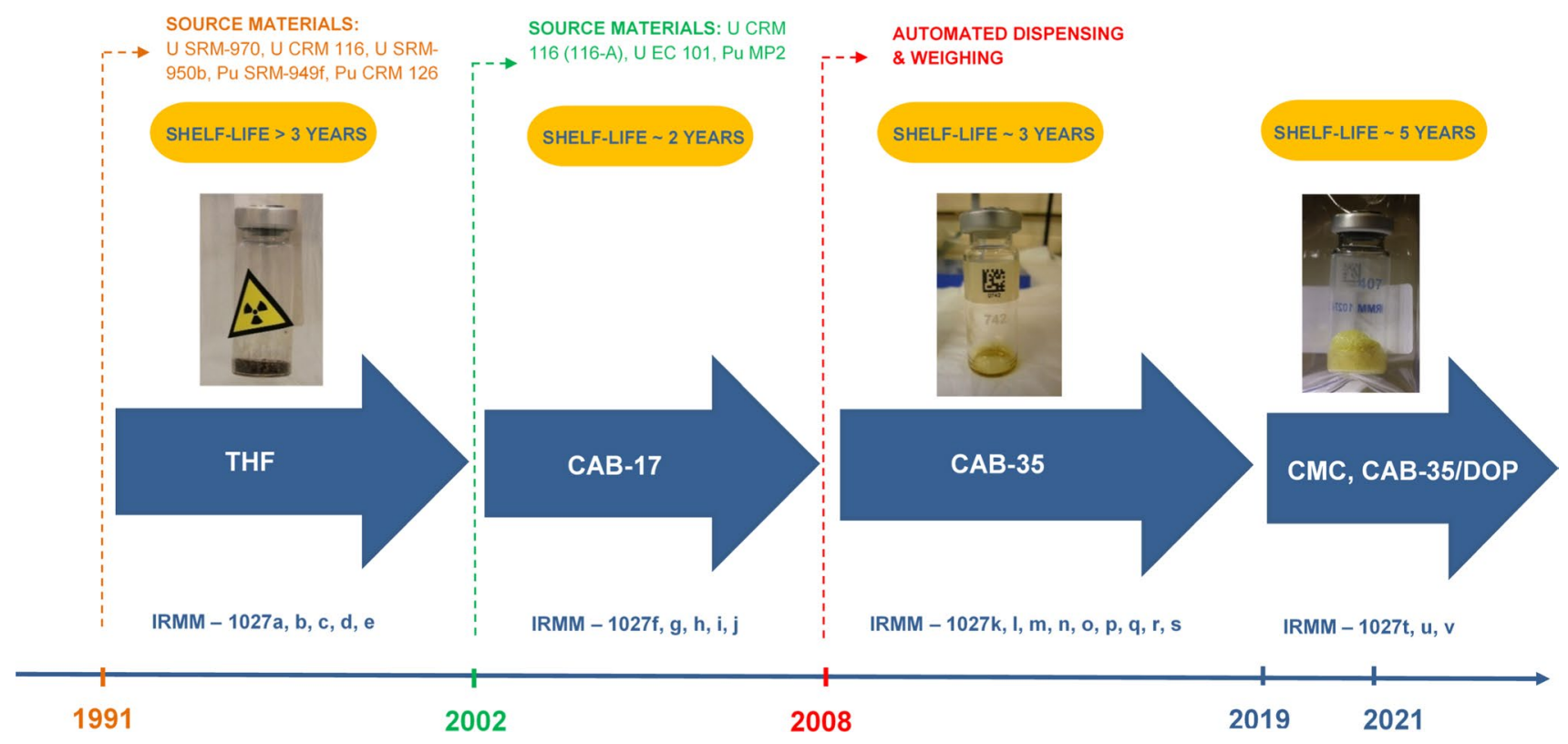

Fig. 1 IRMM-1027 LSD spike developments and improvements (1991-2021)

enriched uranium metal (CRM 116-A, New Brunswick Laboratory, USA) and natural uranium metal (EC NRM 101, European Commission, Belgium) are used as the starting materials to prepare a single stock solution. The plutonium and the enriched uranium metals are cleaned prior to use by electro-polishing [43] and etching, respectively, to remove surface oxidation products.

The plutonium metal is weighed and dissolved in a 3 L quartz flask with $20 \mathrm{~mL} 6 \mathrm{~mol} \mathrm{~L}^{-1}$ hydrochloric acid. After the addition of about $200 \mathrm{~mL}$ of $8 \mathrm{~mol} \mathrm{~L}^{-1}$ nitric acid, enriched and natural uranium metals are weighed and added to the plutonium solution (enrichment $<20 \%{ }^{235} \mathrm{U}$ ). The uranium metals dissolve readily by applying gentle heating. Finally, a solution prepared from deionised water and concentrated nitric acid is added to adjust the concentration of the nitrate solution to about $6 \mathrm{~mol} \mathrm{~L}^{-1}$ and to arrive at $\mathrm{Pu}$ and $\mathrm{U}$ mass fractions of about $0.8 \mathrm{mg} \mathrm{g}^{-1}$ and $20 \mathrm{mg} \mathrm{g}^{-1}$, respectively. The exact concentrations are determined by the weighing of the flask containing the $\mathrm{U} / \mathrm{Pu}$ solution.

Electro-polishing and the dissolution of $\mathrm{Pu}$ metal in $6 \mathrm{~mol} \mathrm{~L}^{-1} \mathrm{HCl}$ was introduced in 2016. The previous protocol using $8 \mathrm{~mol} \mathrm{~L}^{-1}$ nitric acid (and a few drops of $1 \mathrm{~mol}$ $\mathrm{L}^{-1} \mathrm{HF}$ ) for dissolution of Pu did not dissolve the Pu metal completely in all batches. In a few cases, undissolved particles remained at the bottom of the flask. This happened unexpectedly and was not observed in other batches. Consequently, the plutonium content obtained from the mass of the weighed Pu metal could not be verified by IDMS successfully.

Aliquots of about $2.5 \mathrm{~g}$ of the U/Pu solution are dispensed and weighed into individual vials by the automated system [35]. The weighing is performed on an analytical balance (Sartorius TE124S, Göttingen, Germany). A calibrated object, consisting of a vial containing a mass standard, is weighed at regular intervals during dispensing to check the performance of the balance. The nitrate solution in the vials is evaporated to dryness at maximum $55^{\circ} \mathrm{C}$. The humidity in the glove-box is maintained below 20-25\% (relative humidity). After the solution has dried, the organic matrix is applied. As mentioned above, two organic materials are currently used. For the $\mathrm{CAB} /$ DOP procedure, $0.7 \mathrm{~mL}$ of solution (10 g CAB-35, $2 \mathrm{~g}$ DOP and $100 \mathrm{~g}$ acetone) is added, evaporated first at room temperature and then heated to about $45^{\circ} \mathrm{C}$ to dry completely.

For the $\mathrm{CMC}$ procedure, $10 \mathrm{~g}$ of low viscosity CMC sodium salt is added to $90 \mathrm{~g}$ of $2 \mathrm{~mol} \mathrm{~L}^{-1}$ nitric acid solution at $60-70{ }^{\circ} \mathrm{C}$ under continuous stirring. After the dissolution of the $\mathrm{CMC}$ is completed (usually $2-3 \mathrm{~h}$ ), the solution is cooled. $1.5 \mathrm{~mL}$ of this solution is added to the dried nitrates and heated up to about $52-54{ }^{\circ} \mathrm{C}$ to evaporate the nitric acid solution. Once all the nitric acid had evaporated, the CMC foams are produced. Vials are closed with a stopper and an aluminium cap and sealed in a PVC bag. Chemical treatment (evaporation and matrix application) is carried out in well-controlled glove boxes. The preparation of IRMM-1027 LSD spikes is shown in Fig. 2. 


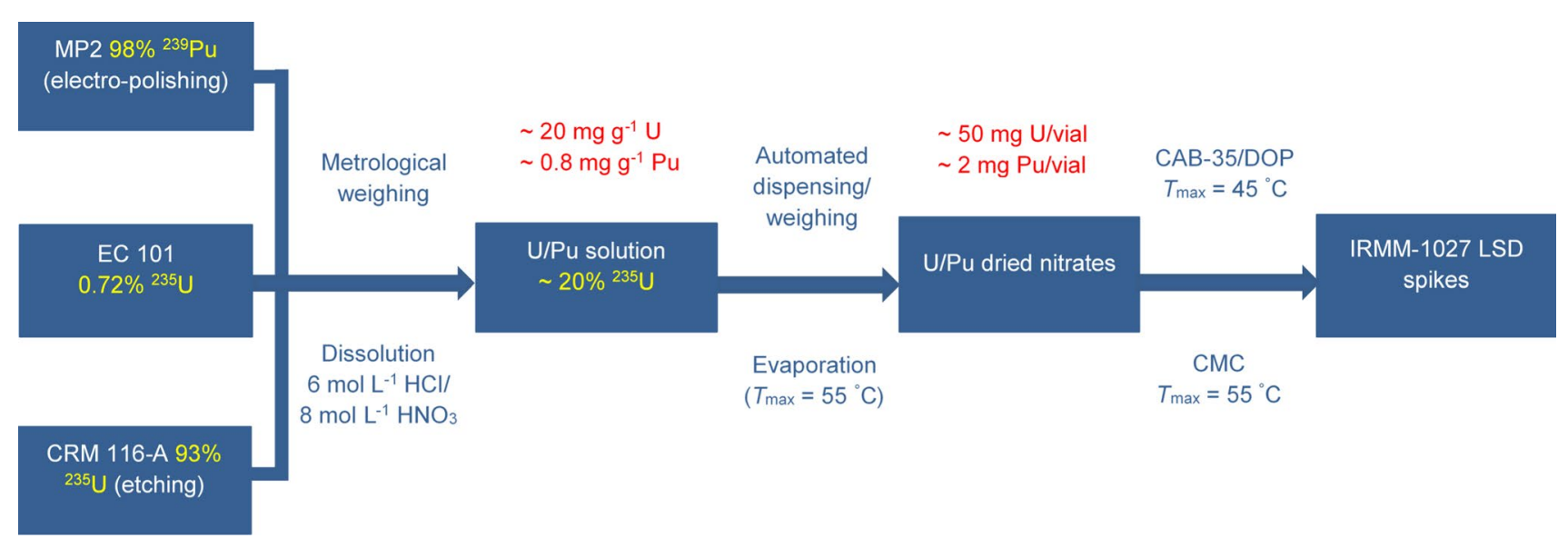

Fig. 2 Preparation of IRMM-1027 LSD spikes

\section{Certification methodology}

\section{Material characterisation}

Characterisation is the process of determining the property values of a reference material. IRMM-1027 LSD spikes are characterised for the masses of ${ }^{239} \mathrm{Pu},{ }^{235} \mathrm{U}$ and ${ }^{238} \mathrm{U}$ per unit and for the $n\left({ }^{234} \mathrm{U}\right) / n\left({ }^{238} \mathrm{U}\right), n\left({ }^{235} \mathrm{U}\right) / n\left({ }^{238} \mathrm{U}\right)$, $n\left({ }^{240} \mathrm{Pu}\right) / n\left({ }^{239} \mathrm{Pu}\right), n\left({ }^{241} \mathrm{Pu}\right) / n\left({ }^{239} \mathrm{Pu}\right)$ and $n\left({ }^{242} \mathrm{Pu}\right) / n\left({ }^{239} \mathrm{Pu}\right)$ amount ratios. The characterisation is established by gravimetric preparation from the starting materials and verified by independent measurements. This allows the certified values and their associated uncertainties to be calculated from the values of the purity and the isotopic composition of uranium and plutonium in the starting materials, and the masses of starting metals, batch solution and dispensed aliquots of solution into each individual unit [44]. As a result, low uncertainties on the assigned values can be obtained. The masses are determined by accurate weighing and corrected for air buoyancy [45-47]. The masses of ${ }^{235} U,{ }^{238} U$ and ${ }^{239} \mathrm{Pu}$ are determined using the equations below.

$m_{239 P u}=\frac{m_{P u M P 2} \cdot \eta_{P u M P 2}}{m_{\text {sol }}} \cdot w_{239 P u M P 2} \cdot m_{\text {aliquot }}$

$m_{235 U}=\frac{m_{U C R M 116 A} \cdot \eta_{U C R M 116 A}+m_{U E C 101} \cdot \eta_{U E C 101}+m_{U M P 2}}{m_{\text {sol }}} \cdot w_{235 \text { Usol }} \cdot m_{\text {aliquot }}$

$m_{238 U}=\frac{m_{U C R M 116 A} \cdot \eta_{U C R M 116 A}+m_{U E C 101} \cdot \eta_{U E C 101}+m_{U M P 2}}{m_{\text {sol }}} \cdot w_{238 U \text { sol }} \cdot m_{\text {aliquot }}$

$m_{U C R M 116 A}, m_{U E C 101} m_{P U M P 2}, m_{U s o l}, m_{\text {aliquot }}$ are the masses of the U CRM 116-A, U EC 101, Pu MP2 metals, the nitrate batch solution and the dispensed aliquot $[\mathrm{g}]$, respectively;
$\eta_{U C R M 116 A}, \eta_{U E C 101}$ and $\eta_{P U M P 2}$ are the purities (e.g. mass fractions) of the U CRM 116-A, U EC 101 and Pu MP2 metals [ $\mathrm{g} \mathrm{g}^{-1}$ ], respectively; $m_{U M P 2}$ is the U mass in Pu MP2 [g] (U impurities, ingrowth). The $w_{235_{U}}, w_{238_{U}}$ and $w_{239_{P_{U}}}$ are the isotope amount fractions (e.g. abundances) of ${ }^{235} \mathrm{U},{ }^{{ }{ }^{3} 8} \mathrm{U}$ and ${ }^{239} \mathrm{Pu}$ in the nitrate batch solution, respectively.

As mentioned earlier, due to incomplete dissolution of $\mathrm{Pu}$ metal in a few cases, some batches of IRMM-1027 LSD spikes had to be characterised by IDMS to assign the certified values.

\section{Confirmation measurements}

Confirmation measurements for the $\mathrm{U}$ and $\mathrm{Pu}$ amount content are carried out by IDMS on aliquots of the batch solution to verify the values established by the gravimetric preparation. A mixed ${ }^{233} \mathrm{U} /{ }^{242} \mathrm{Pu}$ spike CRM, such as IRMM046b or IRMM-046c is used. The isotopic abundances (i.e. ratios) of both elements are measured in unspiked samples by thermal ionisation mass spectrometry (TIMS). This is particularly important to check the mixing and dissolution of the two uranium starting metals (i.e. EC 101 and CRM 116-A). Furthermore, the amount contents of the $\mathrm{U}$ and $\mathrm{Pu}$ are also measured by IDMS in randomly selected vials to

confirm that there was no change in the isotope amount contents before and during dispensing, drying and application of the organic matrix. 
For the IDMS, the spiked and unspiked samples are evaporated to dryness and the oxidation states of plutonium and uranium adjusted to $\mathrm{Pu}(\mathrm{IV})$ and $\mathrm{U}(\mathrm{VI})$, respectively. The sample solution is passed through an anion exchange column (Bio-Rad AG1-X4, 100-200 mesh, Bio-Rad, Hercules, USA) [48, 49]. Uranium is eluted with $8 \mathrm{~mol} \mathrm{~L}^{-1} \mathrm{HNO}_{3}$ and plutonium with $0.35 \mathrm{~mol} \mathrm{~L}-1 \mathrm{HNO}_{3}$. This separation procedure is performed three times to avoid isobaric interferences between ${ }^{238} \mathrm{U}$ and ${ }^{238} \mathrm{Pu}$ in the isotopic measurement. The purified solutions are evaporated, re-dissolved in $1 \mathrm{~mol} \mathrm{~L}^{-1}$ $\mathrm{HNO}_{3}$ and loaded on zone refined rhenium filaments (double configuration). Isotopic measurements are performed by the total evaporation (TE) method on a Triton TIMS (Thermo Fisher Scientific, Bremen, Germany) [50-54]. In this method, the evaporation filament is heated up to maintain a steady intensity and isotopic ratios are measured until the entire sample is consumed (total evaporation). In this way, mass fractionation effects in the ion source are minimised. Isotopic standards (Pu IRMM-290b/A3, U IRMM-074/10) are measured to correct for these mass fractionation effects and to ensure the traceability to the International System of Units (SI). Quality control (QC) samples are measured to check the performance of the mass spectrometer and the IDMS method [55].

\section{Homogeneity assessment}

From 2013 on (IRMM-1027o), the preparation and certification of IRMM-1027 LSD spikes is performed in compliance with ISO 17034 and ISO Guide 35 [14, 15]. By aligning the certification with these standards, additional measurements have been included in the certification process, in particular to assess the homogeneity and stability of the spikes.

The assessment of between-unit variation (heterogeneity) is required to ensure that the assigned certified values are valid for all produced units within the stated uncertainty. Homogeneity is assessed in the final product (i.e. dried spikes) and for all the measurands for which the material is characterised. In the IRMM-1027 series, the measurands are the masses of ${ }^{235} \mathrm{U},{ }^{238} \mathrm{U}$ and ${ }^{239} \mathrm{Pu}$ and the $\mathrm{U}$ and $\mathrm{Pu}$ isotope amount ratios. Units for homogeneity assessment are selected using a random stratified sampling scheme covering the whole batch. The number of selected units depends on the total number of the produced units, usually between 10 and 15 . The ${ }^{235} \mathrm{U},{ }^{238} \mathrm{U}$ and ${ }^{239} \mathrm{Pu}$ amount contents in the selected units are determined by IDMS.

Quantification of between-unit variations (i.e. uncertainty contribution, $s_{\mathrm{bb}}$ ) is accomplished by analysis of variance (ANOVA) using SoftCRM [56, 57], which is one of the recommended statistical approaches of the ISO Guide 35 to estimate the homogeneity. It is important to note that it is not required from the ANOVA test to show equivalence between all units $(\mathrm{CI}=95 \%)$, a "modicum of heterogeneity is acceptable" [58]. It is required, however, that the calculated relative uncertainty contribution associated with inhomogeneity remains below a certain threshold, which is typically $0.05 \%$ for the IRMM-1027 batch. Only if this requirement is fulfilled, shall the LSD batch be considered homogeneous and fit for the intended use.

The homogeneity of the $\mathrm{U}$ and $\mathrm{Pu}$ isotope amount ratios was tested in the IRMM-1027p and IRMM-1027q batches $[33,34]$. Variations in the isotope ratios between different vials are not to be expected. Any change could only stem from a contamination with plutonium and uranium of a different isotopic composition, from the isotope fractionation or from an incomplete dissolution/mixing of the uranium metals. These effects are avoided by carrying out the chemical treatment in separate glove boxes and keeping the drying temperature below $60{ }^{\circ} \mathrm{C}$.

\section{Stability assessment}

Stability testing is necessary to establish conditions for storage (long-term stability) as well as conditions for dispatch to customers (transport or short-term stability) [14, 15]. The term "stability" in this context does not refer to radioactive decay.

The physical stability of the IRMM-1027 series LSD spikes is directly linked to the integrity of the organic matrix (CAB/DOP or CMC). Parameters such as the radiation, the acid residuals, humidity and temperature, light, physical shocks and mechanical stress cause degradation of the stabilising matrix over time. This leads to formation of cracks, flaking and a potential loss of material upon opening the vial. The results of these stability studies have been published elsewhere [30, 31, 37, 39].

With regard to the transport stability, a modified isochronous study was applied. The test samples containing blank CAB/DOP and CMC matrix were stored at $4{ }^{\circ} \mathrm{C}$ and $60{ }^{\circ} \mathrm{C}$ for one week at each temperature $\left(T_{r \text { ef }}=18^{\circ} \mathrm{C}\right)[41]$ and inspected visually. No deterioration of the CAB/DOP appeared in any of the test samples. For the CMC foams, further maturation and discoloration could be observed, but the integrity of the CMC foam remained intact $[36,41]$. This has demonstrated that no degradation is to be expected during the transport of the spikes to the customers. It was assumed that the presence of uranium and plutonium in the matrix would not have significantly affected the stability of the $\mathrm{CAB} / \mathrm{DOP}$ or $\mathrm{CMC}$ spike during transport.

Apart from the physical stability of the spikes, one must demonstrate that the stability of the assigned certified values is guaranteed for the duration of the certificate's validity. This study is usually carried out over an extended period (e.g. 2 years) prior to the release of the reference material. However, as the IRMM-1027 LSD spikes are produced on an annual basis, a different approach had to be taken. The 
long-term stability of assigned values was demonstrated based on the measurement results of IRMM-1027m LSD over a period of four years after certification in the context of the inter-calibration of spike CRMs [48]. Moreover, the stability of the IRMM-1027 series LSD spikes is also studied after the release of the material as part of the postcertification stability monitoring.

\section{Results and discussion}

\section{Confirmation measurements}

The results on the assigned values of more recent batches of IRMM-1027 spikes are discussed in this section.

${ }^{235} \mathrm{U}$ and the ${ }^{239} \mathrm{Pu}$ content measurements in IRMM1027s, IRMM-1027t and IRMM-1027u are shown in Figs. 3 and 4, respectively. Individual results are expressed as the relative difference (bias) from the assigned (certified) value.
Each data point represents an independent measurement result (e.g. chemical treatment, replicate measurements) of the selected unit or an aliquot of the batch solution.

It can be seen from Figs. 3 and 4 that all verification results are in good agreement with the certified value within measurement uncertainties. There was no significant difference observed between the results of the nitrate solution (circles) compared to the selected LSD units with $\mathrm{CAB}$ (squares) and CMC (triangles). Somewhat higher differences were observed for the ${ }^{235} \mathrm{U}$ content in the nitrate solution compared to the vials of IRMM-1027 s. This small difference may be intrinsic to the IRMM-046b spike used in IDMS analysis. All other results were obtained using IRMM-046c spike. The other exception is the ${ }^{239} \mathrm{Pu}$ content in the nitrate solution compared to the units of IRMM-1027u. The same spike ampoule was used for all four aliquots in the IDMS measurement. Therefore, this slight difference $(\sim 0.05 \%)$ might be due to the 'ampoule-to-ampoule' variance of the spike, IRMM-046c.
Fig. 3 Results of the verification of the ${ }^{235} \mathrm{U}$ content in selected IRMM-1027 LSD expressed as the relative difference (bias) from the certified value (CAB vials - brown squares, CMC vials - green triangles, batch solution - empty circles). Error bars represent the associated relative expanded uncertainty $(k=2)$. Red dotted lines show the relative expanded uncertainty $(k=2)$ of the certified value for the respective batch

Fig. 4 Results of the verification of the ${ }^{239} \mathrm{Pu}$ content in selected IRMM-1027 LSD spikes expressed as the relative difference (bias) from the certified value $(\mathrm{CAB}$ vials - brown squares, CMC vials - green triangles, batch solution - empty circles). Error bars represent the associated relative expanded uncertainty $(k=2)$. Red dotted lines show the relative expanded uncertainty $(k=2)$ of the certified value for the respective batch

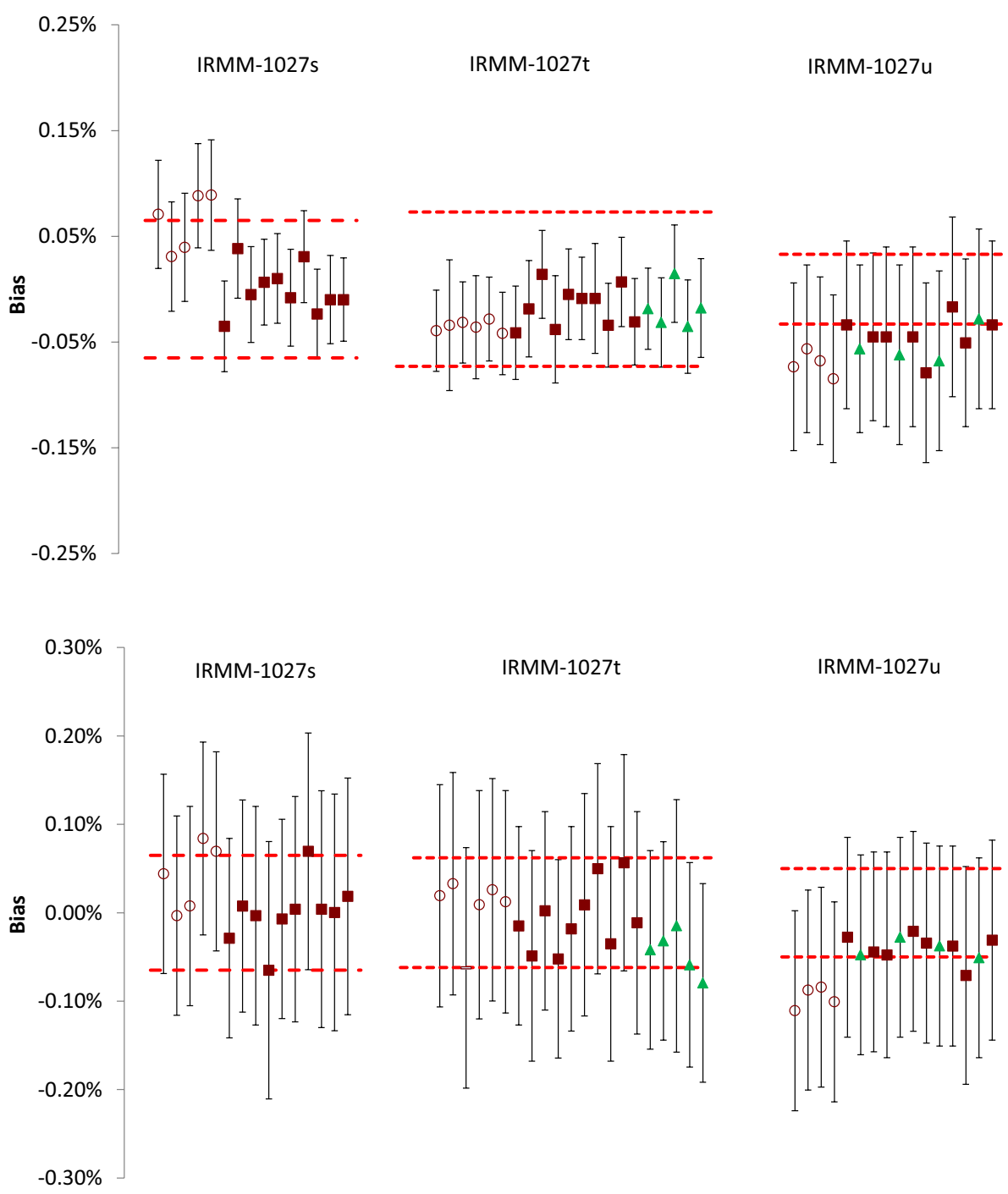


The uncertainties of the ${ }^{239} \mathrm{Pu}$ measurement results are consistent among the different batches. From the IRMM$1027 \mathrm{t}$ batch on, a quality control (QC) sample is measured together with the samples, under the same operating conditions [55]. For the ${ }^{235} \mathrm{U}$ measurement results, IRMM-1027u has slightly larger uncertainty compared to the IRMM-1027s and IRMM-1027t because of an additional uncertainty component coming from the QC sample. Generally, the measurement uncertainties of the ${ }^{239} \mathrm{Pu}$ results are larger than of the ${ }^{235} \mathrm{U}$ results. The reason for this is the larger uncertainty of the Pu IRMM-290b/A3 isotopic standard applied for mass fractionation correction. Figures 3 and 4 also show that the results for the ${ }^{235} \mathrm{U}$ and ${ }^{239} \mathrm{Pu}$ amount contents of the IRMM$1027 \mathrm{u}$ are lower than the certified values, however within the measurement uncertainties. The reason for this observation could not be found despite thorough investigation.

The results of $n\left({ }^{235} \mathrm{U}\right) / n\left({ }^{238} \mathrm{U}\right)$ isotope ratio are shown in Fig. 5. The measured values for the $n\left({ }^{235} \mathrm{U}\right) / n\left({ }^{238} \mathrm{U}\right)$ ratio are systematically higher than the certified values, (except the IRMM-1027s solution), but, for the majority of the results, within measurement uncertainty. The results of the respective QC sample did not show this observation; therefore, a measurement error could be excluded. The reason could be explained by a possible contamination with enriched uranium during the sample preparation prior to the measurement.

The verification results have demonstrated that the dispensing by an automated system and subsequent drying of the nitrate solution is well under control, and that the application of $\mathrm{CAB} / \mathrm{DOP}$ and $\mathrm{CMC}$ organic matrices have no significant effect on the IDMS results. These results support conclusions already observed in the previous batches of IRMM-1027 LSD spikes [17].

JRC Geel, JRC Karlsruhe, operating the EURATOM onsite laboratories, and the IAEA, operating the IAEA on-site laboratory, are engaged in mutual verification of mixed uranium/plutonium LSD spikes in the frame of the European
Commission support programme task to the IAEA [17] These external verification measurements are valuable and highly appreciated as they support the certified values and thus underpin that the IRMM-1027 series is fit for purpose for fissile material accountancy and control. Some of these external verification results are published in [17].

\section{Stability measurements}

The stability of the assigned values of the IRMM-1027 series LSD spikes has been monitored using (ID)-TIMS as part of the post-certification stability study since 2013 . Several units of the respective batch are measured for the $U$ and $\mathrm{Pu}$ amount contents and for the $\mathrm{U}$ and $\mathrm{Pu}$ isotope ratios for the duration of the certificate's validity ( 3 years for LSD batches until IRMM-1027s and 5 years from IRMM-1027t onwards). The results for the ${ }^{235} \mathrm{U}$ mass fraction in IRMM1027o are shown in Fig. 6.

It can be seen from Fig. 6 that the assigned values for the ${ }^{235} \mathrm{U}$ mass fraction could be verified within uncertainties and, therefore, the stability could be demonstrated successfully, even beyond the three years of the certificate' validity.

The compatibility between the stability result $\left(y_{\text {stab }}\right)$ and the certified value $\left(y_{\text {cert }}\right)$ can also be quantified by the normalized deviation $\left(E_{\mathrm{n}}\right.$ score $)$ [59]

$E_{n}=\frac{y_{\text {stab }}-y_{\text {cert }}}{\sqrt{u^{2}\left(y_{\text {stab }}\right)+u^{2}\left(y_{\text {cert }}\right)}}$

where $u\left(y_{\text {stab }}\right)$ is the standard uncertainty of the results of the stability measurement and $u\left(y_{\text {cert }}\right)$ the standard uncertainty of the certified value. An absolute value of $E_{n}$ less than 2 means that there is no significant difference between the two values $y_{\text {stab }}$ and $y_{\text {cert }}$ demonstrating stability. The results of the stability monitoring of the respective LSD batch are summarised in Table 1.
Fig. 5 Results of the verification of the $n\left({ }^{235} \mathrm{U}\right) / n\left({ }^{238} \mathrm{U}\right)$ isotope ratio in selected IRMM1027 LSD expressed as the relative difference (bias) from the certified value $(\mathrm{CAB}$ vials - brown squares, CMC vials green triangles, batch solution - empty circles). Error bars represent the associated relative expanded uncertainty $(k=2)$. Red dotted lines show the relative expanded uncertainty $(k=2)$ of the certified value for the respective batch

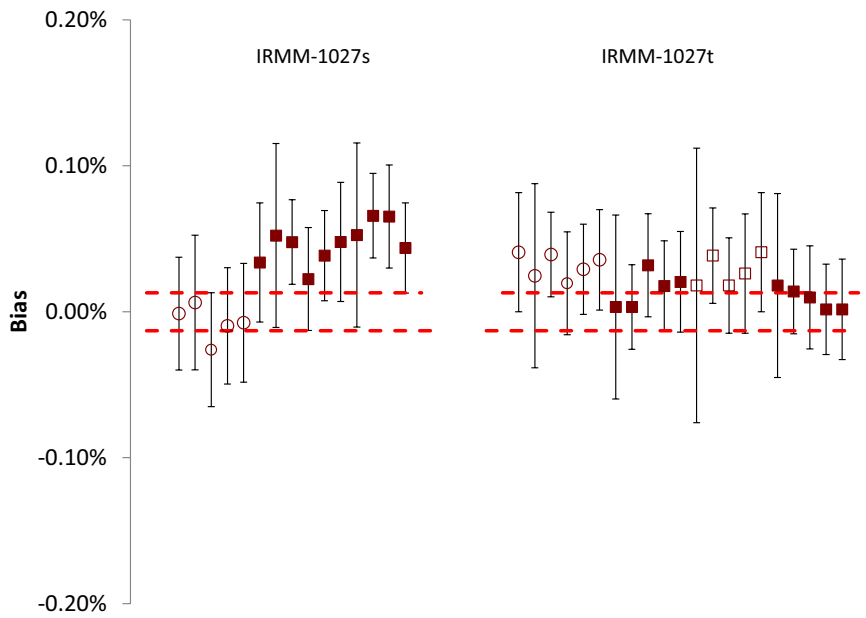




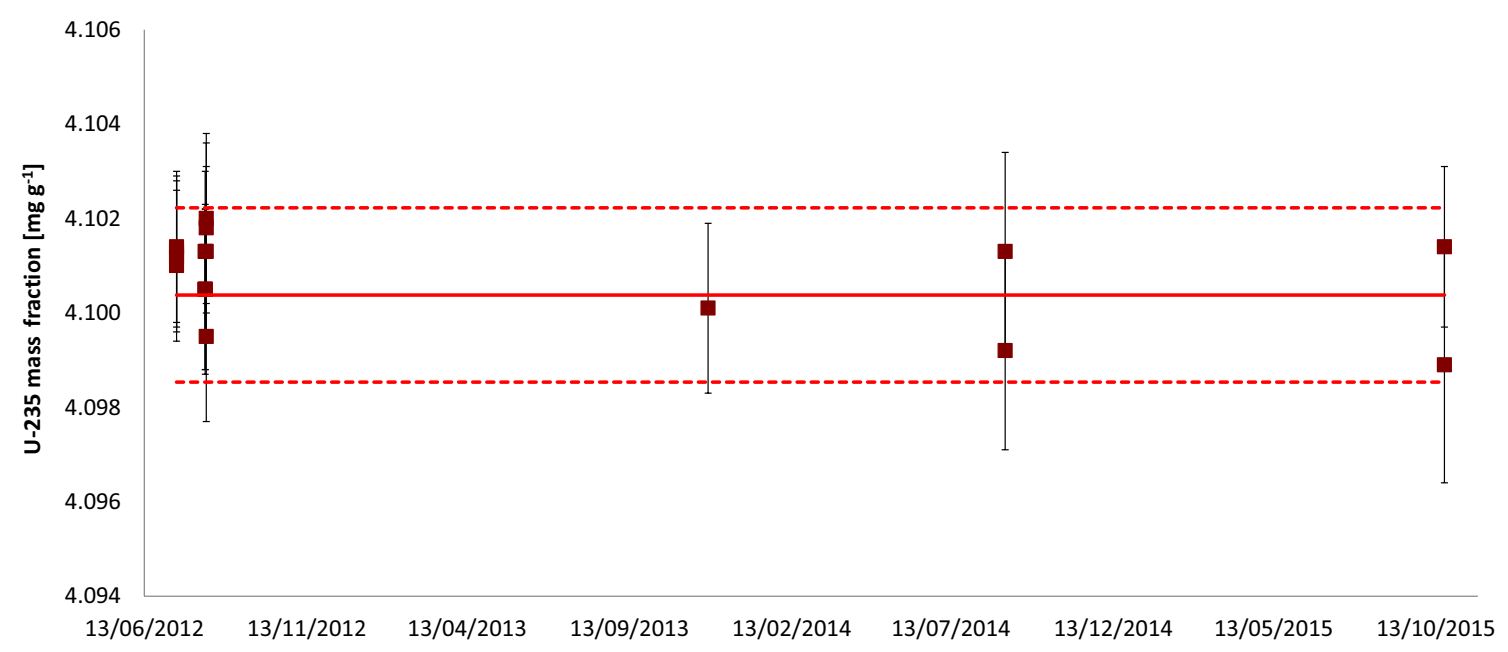

Fig. $6{ }^{235} \mathrm{U}$ mass fraction in IRMM-1027o as a function of time ( $t=3.3$ years). Red straight and dotted lines show the certified value and its expanded uncertainty $(k=2)$

Table 1 Results of the stability monitoring $\left(E_{\mathrm{n}}\right.$ score $)$ for the IRMM-1027 LSD spikes

\begin{tabular}{llllll}
\hline Batch LSD & Year & ${ }^{239} \mathrm{Pu}$ content & ${ }^{235} \mathrm{U}$ content & $\begin{array}{l}n\left({ }^{240} \mathrm{Pu}\right) / n\left({ }^{239} \mathrm{Pu}\right) \\
\text { ratio }\end{array}$ & $\begin{array}{l}n\left({ }^{235} \mathrm{U}\right) / n\left({ }^{238} \mathrm{U}\right) \\
\text { ratio }\end{array}$ \\
\hline IRMM-1027o & 2012 & 0.67 & 0.63 & 0.08 & 1.01 \\
& 2013 & 1.69 & 0.22 & 0.68 & 1.89 \\
& 2014 & 0.26 & 0.75 & 0.65 & 1.74 \\
& 2015 & 2.29 & 0.88 & 0.23 & 2.36 \\
IRMM-1027p & 2016 & 0.62 & $/$ & $/$ & $/$ \\
& 2013 & 1.16 & 1.04 & 0.51 & 1.48 \\
& 2014 & 1.82 & 0.65 & 0.27 & 0.76 \\
IRMM-1027q & 2015 & 1.01 & 1.17 & 0.02 & 0.23 \\
& 2017 & $/$ & $/$ & 0.97 & 1.13 \\
IRMM-1027r & 2015 & 1.76 & 0.88 & 0.34 & 0.63 \\
& 2017 & 1.63 & 1.35 & 0.43 & 0.71 \\
& 2015 & 0.4 & 1.51 & 0.24 & 0.98 \\
& 2017 & 1.85 & 1.36 & 1.16 & 0.63 \\
IRMM-1027s & 2019 & 0.23 & 1.61 & 1.23 & 1.96 \\
& 2017 & 0.33 & 0.93 & 0.12 & 2.27 \\
& 0.55 & 0.49 & 0.57 & 2.8 \\
\hline
\end{tabular}

These results confirm that the assigned certified values could be verified within measurement uncertainties for the majority of the results, except for the $n\left({ }^{235} \mathrm{U}\right) / n\left({ }^{238} \mathrm{U}\right)$ ratio, where in some cases the $E_{n}$ score was higher than 2. Detailed examination of the results showed that the measured ratios were higher than the certified values. A similar deviation has been observed in previous batches of LSD spikes (see also Fig. 5) [17]. $E_{\mathrm{n}}$ score larger than 2 could be due to the somewhat small (and possibly underestimated) uncertainty. Therefore, it was concluded that there is no long-term stability problem with the $n\left({ }^{235} \mathrm{U}\right) / n\left({ }^{238} \mathrm{U}\right)$ isotope ratio and it is rather the consequence of the slight positive bias between verification and the gravimetrically certified values that persists since the time of preparation.

\section{Assigned values and uncertainties}

The uncertainties associated with the certified values were estimated in accordance with the Guide to the Expression of Uncertainty in Measurement GUM and ISO Guide 35:2017 $[15,44]$. They consist of contributions due to characterisation (purity, isotopic composition, masses of the metals, solution and dispensed aliquots) and contributions from the between-unit heterogeneity assessment. The uncertainties 
due to possible degradation during transport and long-term storage were found to be negligible ( $u_{\mathrm{lts}}=0$ and $\left.u_{\mathrm{sts}}=0\right)$. The contributions were combined to estimate the expanded uncertainty of the certified value as:

$U_{C R M}=k \cdot \sqrt{u_{c h a r}^{2}+u_{b b}^{2}}$

where $U_{\mathrm{CRM}}$ is the expanded uncertainty of the certified value, that corresponds to a level of confidence of about $95 \%, k$ is the coverage factor, $u_{\text {char }}$ is the combined standard uncertainty of the characterisation study and $u_{\mathrm{bb}}$ is the estimated uncertainty associated with the heterogeneity. An overview of relative standard uncertainties of the certified values in various IRMM-1027 batches are shown in Fig. 7. Relative standard uncertainties are shown for comparison with the ITV 2010 values.

It can be seen from Fig. 7 that earlier batches had higher uncertainties of the certified values, in particular for the mass of ${ }^{235} \mathrm{U}$ and ${ }^{239} \mathrm{Pu}$ content and the $n\left({ }^{240} \mathrm{Pu}\right) / n\left({ }^{239} \mathrm{Pu}\right)$ isotope ratio. The reason for this was the different starting materials used for the preparation and the fact that these materials were not certified for isotopic composition. Consequently, isotopic abundances had to be measured on mass spectrometers and corrected for mass fractionation. At that time, different mass spectrometers and methods were used compared to nowadays. Since the batch IRMM-1027f, the metals U EC 101, U CRM 116 (CRM 116-A) and Pu MP2 certified metals with smaller uncertainties on the purity and isotope ratios have been used. As a result, uncertainties lower than $0.04 \%$ were obtained, with the exception of IRMM-1027g and IRMM-1027s, where the assignment of the values was based on the IDMS. Since IRMM-1027o, the uncertainty from the homogeneity assessment has been included in the overall uncertainty. This led to a small increase in the uncertainties of the masses of ${ }^{235} \mathrm{U},{ }^{238} \mathrm{U}$ and ${ }^{239} \mathrm{Pu}$.

These uncertainties are acceptably small, and enable laboratories using these spikes to achieve their measurement results with uncertainties below the ITVs-2010. The ITV2010 target values for plutonium and uranium by IDMS are $0.18 \%$ or $0.28 \%$ (expressed as relative standard uncertainty) for glove-box and hot-cell conditions, respectively. They take into account actual practical experience and should be achievable under routine measurement conditions. The current issue of the International Target Values (ITV-2010) represents the sixth revision of the Target Values for the uncertainty component in destructive analytical methods, first issued in 1979 to the safeguards authorities of EURATOM and of the IAEA by the Working Group on Techniques and Standards for Destructive Analysis (WGDA) of the European Safeguards Research and Development Association (ESARDA) the ESARDA/WGDA.

\section{Future considerations}

The accuracy of IDMS measurements depends not only on the quality of the spikes but it is also limited by the intrinsic precision of the IDMS (i.e. error magnification factor) [5, 13]. Spikes for IDMS must be of suitable size and isotopic composition in order to reach the required accuracy. The ratio between spike and sample (spike to sample ratio) can affect the uncertainty of the measurement result, particularly if this ratio is not optimised for the sample to be analysed $[5,13]$.

The present composition of IRMM-1027 LSD spikes is suitable for the measurement of a wide range of typical

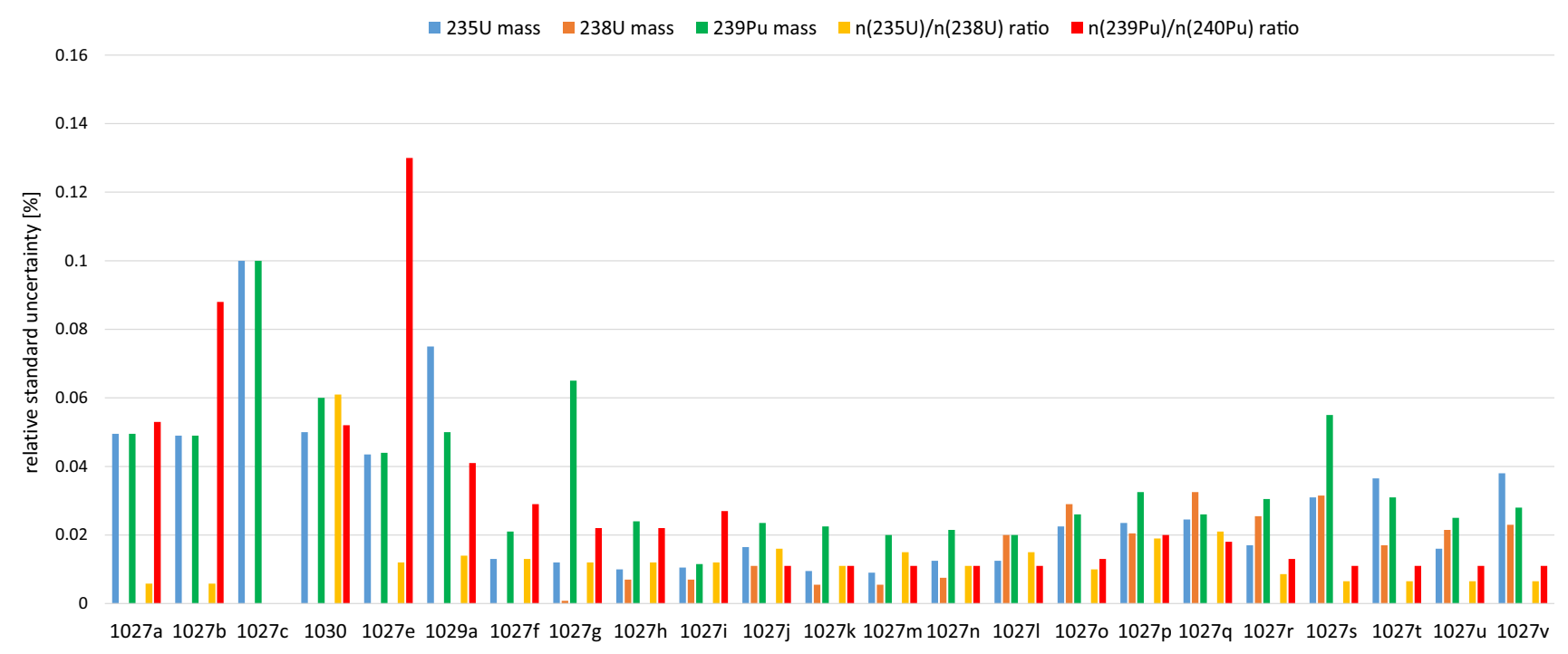

Fig. 7 An overview of relative standard uncertainties in batches of LSD spikes (IRMM-1027a to IRMM-1027v) 
dissolved fuel. At the same time, the fulfilment of regulatory and policy rules regarding the $\mathrm{U}$ and $\mathrm{Pu}$ amounts and the ${ }^{235} \mathrm{U}$ enrichment limitation $\left(<20 \%{ }^{235} \mathrm{U}\right)$ had to be ensured. From these perspectives, the IRMM-1027 LSD series is a compromise. For the measurement of mixed oxide (MOX) fuels, another type of LSD spike with a ratio 1:1 U/ $\mathrm{Pu}(20 \mathrm{mg} \mathrm{U}$ and $20 \mathrm{mg} \mathrm{Pu}$ ) ratio was produced only once (IRMM-1029a) [12].

Since 2008, bi-annual meetings are held between the LSD spikes producers and users to discuss current status, future needs and improvements of LSD spikes. Recently, LSD spikes with different $\mathrm{U} / \mathrm{Pu}$ ratios and ${ }^{235} \mathrm{U}$ enrichments have been requested, for an example a spike with ${ }^{235} \mathrm{U}$ enrichment level up to $80 \%$. This would allow LSD users at reprocessing plants to reduce further the uncertainties of their IDMS measurements. Another example is an LSD spike with natural $\mathrm{U}$ only for analysis of high-enriched samples $\left(>90 \%{ }^{235} \mathrm{U}\right)$.

Another issue for LSD producers to consider in the future is the availability of starting metals with suitable purity and small uncertainties. The present LSD spikes require considerable amounts of high quality metals, especially of $\mathrm{Pu}$ metal for which the global supply is limited and not easily guaranteed in the future. Shipments are also becoming more difficult due to stricter regulations.

An "alternative LSD spike" has been proposed by Roger Wellum in 2008. This proposal relies on a ${ }^{235} \mathrm{U}$ spike alone with measurements of Pu being carried out on the diluted sample. In this approach, the uranium content in the original fuel solution is determined using a ${ }^{235} \mathrm{U}$ LSD spike. A small sample of the fuel solution is diluted and the $\mathrm{U}$ and $\mathrm{Pu}$ contents in the diluted sample are measured by IDMS after spiking with small spikes (e.g. ${ }^{242} \mathrm{Pu},{ }^{233} \mathrm{U}$ ). The dilution factor is calculated from the ${ }^{238} \mathrm{U}$ concentration in the original and the diluted fuel solutions. From the Pu concentration in the diluted sample and the established dilution factor, the $\mathrm{Pu}$ content in the original solution can be determined. The advantage of this concept is that no large (milligram) amounts of ${ }^{239} \mathrm{Pu}$ are needed for the spike, and thus, the consumption of the ${ }^{239} \mathrm{Pu}$ metal is reduced. On the other hand, a greater selection of liquid spikes is needed to measure the diluted samples accurately. Guaranteeing the availability of ${ }^{233} \mathrm{U}$ spikes could be a particular challenge when choosing this approach.

\section{Conclusions}

EURATOM safeguards have the status of European law (Chapter VII of the EURATOM Treaty) and include verification of the nuclear material accountancy of nuclear facility operators. The IRMM-1027 LSD spikes are tailor-made reference materials developed and optimised for the measurement of the uranium and plutonium content in dissolved fuel solutions by IDMS. They have been supplied to EURATOM safeguards and partners from industry for 30 years, meeting the JRC's support as established in the EURATOM Treaty. They are produced in compliance with ISO 17034. A special emphasis was given over time to the stability and homogeneity assessment, and the corresponding uncertainty contributions were included in the combined uncertainty of the reference material. These uncertainties are fit for safeguards purposes, as acknowledged by LSD spike users. In recent years efforts have been made to extend the stability of LSD spikes and thus, the validity of the material's certificate.

By providing measurement quality control tools, such as the IRMM-1027 LSD spike series, the JRC is directly contributing to the effectiveness of nuclear safeguards systems, supporting operators in their accountancy and the authorities in meeting the challenge to achieve the required high level of detection probability [59].

Acknowledgements The authors would like to thank Roger Wellum for his valuable comments on the paper and for establishing a GUM based uncertainty calculation approach at the JRC Geel. The authors would like to thank Saskia Werelds and Theo Drooghmans for their technical assistance throughout the LSD project. The authors would also like to thank former colleagues at the JRC Geel, Paul de Bievre, Klaus Mayer, André Verbruggen, Roger Eykens, Adolfo Alonso-Muñoz, Heinz Kühn, Willy Lycke, Ramon Garcia Galan, Jan Broothaerts, Frans Hendrickx, Naoki Surugaya, Soichi Sato, Yoshi Kushigeta, Célia Venchiarutti and Sébastien Mialle for their contributions to the LSD spike project. The authors would also like to thank Lisa Colletti from Los Alamos National Laboratory (LANL) for assistance in the implementation of the electro-polishing technique for the plutonium metal. The authors would like to thank colleagues from the Analytical Service of the JRC Karlsruhe and the Nuclear Material Laboratory of the IAEA for carrying out the external verification measurements in the scope of the European Commission Support task to the IAEA. Finally, we would like to acknowledge the valuable feedback from the IRMM-1027 LSD users during these thirty years.

Open Access This article is licensed under a Creative Commons Attribution 4.0 International License, which permits use, sharing, adaptation, distribution and reproduction in any medium or format, as long as you give appropriate credit to the original author(s) and the source, provide a link to the Creative Commons licence, and indicate if changes were made. The images or other third party material in this article are included in the article's Creative Commons licence, unless indicated otherwise in a credit line to the material. If material is not included in the article's Creative Commons licence and your intended use is not permitted by statutory regulation or exceeds the permitted use, you will need to obtain permission directly from the copyright holder. To view a copy of this licence, visit http://creativecommons.org/licenses/by/4.0/. 


\section{References}

1. The structure and content of agreements between the agency and states required in connection with the Treaty on non-proliferation of nuclear weapons, INFCIRC/153 (corrected), Vienna, June 1972

2. Consolidated version of the treaty establishing the European Atomic Energy Community, Official Journal of the European Union, 2012/C 327/01, 2012

3. Aggarwal SK, Duggal RK, Rao R, Jain HC (1986) Comparative study of plutonoium-239, plutonium-240 and plutonium-242 spikes for determining plutonium concentration by isotope dilution-thermal ionisation mass spectrometry. Int J Mass Spectrom Ion Processes 71:221-231

4. De Bievre P, Van Audenhove J (1976) An accurate procedure to safeguard the fissile material content of input and output solutions of reprocessing plants; in proceedings of the IAEA International symposium on safeguarding of fissile material. IAEA SM 201(108):493-497

5. De Bievre PJ, Debus GH (1965) Precision mass spectrometric isotope dilution analysis. Nucl Instrum Methods 32:224-228

6. Lycke W, Gallet M, Peetermans F, Damen R, Bouwmeester E, De Bievre P, Van Audenhove J (1979) Accurate in situ assay of total fissile isotopes in inputs of reprocessing plants: a reference method or a definitive method? NBS Special Publications 1:582

7. Raptis $\mathrm{K}$, Alonso A, Ingelbrecht $\mathrm{C}$, Verbruggen $\mathrm{A}$, Wellum $\mathrm{R}$ (1999) The preparation of metal spikes for IDMS of reprocessing input solutions; In proceedings of ESARDA Symposium on Safeguards and Nuclear Material Management, Seville, Spain, $589-592$

8. Berger J, Doubek N, Jamet G, Donohue D, Bagliano G, Mayer K, Verbruggen A, Ingelbrecht C, Hendrickx F, Alonso A, De Bievre, Ahrenz HJ (1995) Development and experience with ${ }^{235} \mathrm{U}$ and ${ }^{239} \mathrm{Pu}$ solid spikes for IDMS of spent fuel solution; in proceedings of ESARDA Symposium on Safeguards and Nuclear Material Management, Aachen, Germany, 9-11

9. Jammet G, Zoigner A, Doubek N, Aigner H, Deron S, Bagliano G (1990) Preparation and provisional validation of a large size dried spike: batch SAL-9934; IAEA/AL/029: International Atomic Energy Agency

10. Bagliano G, Cappis J, Doubek N, Jammet G, Raab W, Zoigner A (1989) Preparation and validation of a large size dried spike: batch SAL-9924; IAEA/AL/025: International Atomic Energy Agency

11. Verbruggen A, Hendrickx F, Alonso A, Mayer K, De Bievre P (1993) Solid spikes for input analysis; in proceedings of 15 th Annual ESARDA meeting, Rome, Italy, 277-280

12. Vebruggen A, Alonso-Munoz A, Edgan D, Hendrickx F, Sato S, Wellum R (1999) Solid spikes for analysis of input solutions of reprocessing plants; In proceedings of ESARDA Symposium on Safeguards and Nuclear Material Management, Seville, Spain, 597-603

13. De Bievre P, Ingelbrecht C, Verbruggen A, Orea-Rocha JM, Barrandon JN (1991) Solid spikes from CBNM for input analysis; in proceedings of 13th Annual ESARDA meeting, Avignone, France

14. ISO 17034 (2017) General requirements for the competence of reference materials producers; International Organization for Standardization, Geneva, Switzerland

15. ISO Guide 35 (2015) Reference materials - Guidance for characterisation and assessment of homogeneity and stability; International Organization for Standardization, Geneva, Switzerland

16. Kuhn E, Deron S, Bagliano G, Cappis J, Kuno Y, Kurosawa A, Kamata, Akiyama M, Tsutaki Y, Suzuki T (1990) The use of large size dried spikes for accountability measurements of reprocessing input solutions; STR-259, International Atomic Energy Agency

17. Jakopic R, Aregbe Y, Richter S, Zuleger E, Mialle S, Balsley SD, Repinc U, Hiess J (2017) Verification measurements of the
IRMM-1027 and the IAEA large-sized dried (LSD) spikes. J Radioanal Nucl Chem 311:1781-1791

18. Surugawa N, Hiyama T, Verbruggen A, Wellum R (2008) Preparation, certification and validation of stable solid spike of uranium and plutonium coated with a cellulose derivative for the measurement of uranium and plutonium content in dissolved nuclear fuel by dilution mass spectrometry. Anal Sci 24:247-252

19. Jakopič R, Aregbe Y, Buják R, Richter S, Buda R, Zuleger E (2015) Results of the REIMEP-17 inter-laboratory comparison for the measurement of the $\mathrm{U}$ and $\mathrm{Pu}$ amount content and isotope amount ratios in the synthetic dissolved spent nuclear fuel solution. Accred Qual Assur 20:421-429

20. Casteleyn K, Duislaeger L, Boella M, Chare P, Lipcsei F, Schwalbach P, Synetos S, Enright T, Le Terrier A, Luetzenkirchen K, Van Belle P, Zuleger E, Aregbe Y (2011) On-site laboratories of Euratom: ten years of excellent results and time to renew, in Proceedings of the INMM annual meeting

21. IAEA-STR-368 (2010) International target values 2010 for measurement uncertainties in safeguarding nuclear materials; Vienna

22. Orea Rocha JM, Ingelbrecht C, Criado Portal AJ (1993) Uraniumplutonium metallic spikes for IDMS accountancy measurements: preparation and characterization. Nucl Instrum Methods Phys Res A334:96-100

23. Ingelbrecht C, Edgan D, Peetermans F, Verbruggen A (1997) New $\mathrm{U} / \mathrm{Pu}$ metallic spikes for safeguards accountancy measurements at reprocessing plants. Nucl Inst Methods Phys Res A 397:30-33

24. 1993 international target values for uncertainty components in fissile isotope and element accountancy for the effective safeguarding of nuclear materials; Journal of Nuclear Materials Management, January 1994

25. IAEA-STR-327 (2001) International target values 2000 for measurement uncertainties in safeguarding nuclear materials; Vienna

26. Laszlo G, De Ridder P, Goldman A, Cappis J, De Bievre P (1991) Optimal sample to tracer ratio for isotope dilution mass spectrometry: the polyisotopic case; In proceedings of ESARDA Symposium on Safeguards and Nuclear Material Management, Avignon, France

27. Alonso A, Eykens R, Kehoe F, Kuhn H, Surugaya N, Verbruggen A, Wellum R (2002) Preparation and certification of new type of large size dried spikes: batch IRMM-1027f; GE/R/IM/36/2002

28. https://echa.europa.eu/nl/substance-information/-/substanceinfo/ 100.003.389

29. Edgar KJ, Buchanan CM, Debenham JS, Rundquist PA, Seiler BD, Shelton MC, Tindall D (2001) Advances of cellulose ester performance and application; Prog. Polym Sci 24:247-252

30. Buják R, Delva L, Erkoc M, Bauwens J, Jakopič R, Vincze L, Aregbe Y, Cardon L (2017) Long-term stability of cellulose acetate butyrate thin films for nuclear certified reference materials. J Radioanal Nucl Chem 311:877-886

31. Bujak R, Bauwens J, Jakopic R, De Groote M, Cardon L, Aregbe Y (2013) Investigation on the long-term stability of IRMM-1027 series of Large-sized dried (LSD) spikes; ESARDA Bulletin, No. 49

32. Jakopič R, Bauwens J, Buják R, Eykens R, Hennessy C, Kehoe F, Kuhn H, Richter S, Aregbe Y (2013) Preparation and certification of Large-sized Dried (LSD) spike IRMM-1027o; EUR 25857 EN

33. Jakopič R, Bauwens J, Buják R, Eykens R, Hennessy C, Kehoe F, Mialle S, Venchiarutti C, Richter S, Aregbe Y (2014) Preparation and certification of Large-sized Dried (LSD) spike IRMM-1027p; EUR $26520 \mathrm{EN}$

34. Jakopič R, Bauwens J, Hennessy C, Kehoe F, Jacobsson U, Richter S, Aregbe Y (2015) Preparation and certification of Large-sized Dried (LSD) spike IRMM-1027q; EUR 27211 EN

35. Verbruggen A, Bauwens Van De Steene JN, Jacobsson U, Eykens R, Wellum R, Aregbe Y (2008) An automated system for the 
preparation of Large Size Dried (LSD) spikes; proceedings in ATALANTE. France, Montpellier

36. Aregbe Y, Banik NL, Bauwens J, Buda R, Buják R, Carlos Marquez R, Casteleyn K, Duinslaeger L, Kehoe F, Hennessy C, Jakopič R, Sánchez Hernández AM, Tóth K, Zuleger E (2018) INS-CRM: Innovative nuclear certified reference materials (CRM) for EURATOM safeguards and industry; Scientific Report - JRC114518

37. Carlos R, Buda R, Lützenkirchen K, Hernández AS, Van Belle P (2015) Stabilisation of uranium/plutonium dried spikes with a cellulosematrix; Proceedings of 37th ESARDA Symposium on Safeguards and Nuclear Non-Proliferation

38. Sanchez AM, Toth K, Aregbe Y, Banik NL, Bauwens J, Buda R, Bujak R, Carlos Marquez R, Casteleyn K, Duislaeger L, Hennessy C, Jakopic R, Kehoe F, Van Belle P, Zuleger E (2017) Alternative nuclear certified reference materials for safeguards and industry; 39th ESARDA Annual Meeting: Symposium, proceeding paper. Dusseldorf, Germany

39. Toth K, Bujak R, Sanchez Hernandez AM, Bauwens J, Carlos Marquez R, Buda R, Banik NL, Jakopič R, Zuleger E, Aregbe Y (2018) Research on long-term stability of mixed U and Pu largesized dried (LSD) spikes for fissile material control. Progress in Nuclear Science and Technology 5:48-51

40. https://ec.europa.eu/jrc/en/science-update/jrc-releases-irmm1027t-and-irmm-1027u-new-type-large-sized-dried-spike-refer ence-material

41. Jakopič R, Bauwens J, Buják R, Hennessy C, Kehoe F, Jacobsson U, Toth K, Richter S, Aregbe Y (2019) Preparation and certification of Large-sized Dried (LSD) spike IRMM-1027t; EUR 29742 EN

42. Buják R, Toth K, Bauwens J, Hennessy C, Kehoe F, Jacobsson U, Richter S, Aregbe Y (2020) Preparation and certification of Large-sized Dried (LSD) spike IRMM-1027u; EUR 30137 EN

43. Jakopič R, Bauwens J, Buják R, Hennessy C, Kehoe F, Jacobsson U, Richter S, Aregbe Y (2018) Preparation and certification of Large-sized Dried (LSD) spike IRMM-1027s; EUR 29274 EN

44. ISO/IEC Guide 98-3 (2008) Guide to the Expression of Uncertainty in Measurement (GUM, 1995); International Organization for Standardization, Geneva, Switzerland

45. Guidelines on the calibration of non/automatic weighing instruments (03/2011) EURAMET cg-18, Version 3.0.

46. OIML R111-1 (2004) Weights of classes E1, E2, F1, F2, M1, M1-2, M2, M2-3 and M3, Part 1: Metrological and technical requirements; international organisation of legal metrology, Paris, France

47. Davidson S, Perkin M, Buckley M; Measurement Good Practice Guide No. 71, The Measurement of Mass and Weight; National Physical Laboratory, Teddington, Middlesex, UK, 2004.

48. Jakopic R, Verbruggen A, Eykens R, Kehoe F, Kuhn H, Kushigeta Y, Jacobsson U, Bauwens J, Richter S, Wellum R, Aregbe
Y (2010) An inter-calibration campaign using various selected $\mathrm{Pu}$ spike isotopic reference materials. J Radioanal Nucl Chem 286:449-454

49. Jakopic R, Bauwens J, Richter S, Sturm M, Verbruggen A, Wellum R, Eykens R, Kehoe F, Kuhn H, Aregbe Y (2011) Preparation and development of new Pu spike isotopic reference materials at IRMM; ESARDA Bulletin, No. 46

50. Callis EL, Abernathey RM (1991) High precision isotopic analyses of uranium and plutonium by total sample volatilization and signal integration. IntJ Mass Spec Ion Processes 103:322-327

51. Richter S, Goldberg SA (2003) Improved techniques for high accuracy isotope ratio measurement of nuclear materials using thermal ionization mass spectrometry. Int J Mass Spectrom 229:181-197

52. Bürger S, Balsley SD, Baumann SD, Berger J, Boulyga SF, Cunningham JA, Kappel S, Koepf A, Poths J (2012) Uranium and plutonium analysis of nuclear material samples by multi-collector thermal ionization mass spectrometry: quality control, measurement uncertainty, and metrological traceability; Int. J Mass Spectrom 311:40-50

53. Boulyga S, Konegger-Kappel S, Richter S, Sangely L (2015) Mass spectrometric analysis for nuclear safeguards. J Anal At Spectrom 30:1469-1489

54. C1672-17: Standard test method for determination of uranium and plutonium isotopic composition or concentration by total evaporation method using a thermal ionisation mass spectrometer; ASTM International.

55. Venchiarutti C, Jakopič R, Hennessy C, Toth K (2021) Preparation and characterisation of uranium and plutonium quality control samples for isotope dilution mass spectrometry measurements and uncertainty estimation. J Radioanal Nucl Chem 327:1305-1316

56. SoftCRM Version 2.0.10 (2000) SoftCRM2/revised version. Developed by NHRF (Bonas G, Zervou M, Papaeoannou T) and JRC-IRMM (Linsinger T)

57. Linsinger TPJ, Pauwels J, Van der Veen AMH, Schimmel H, Lamberty A (2001) Homogeneity and stability of reference materials. Accred Qual Assur 6:20-25

58. ISO/IEC Guide 98-6 (2021) Uncertainty of measurement Part 6: Developing and using measurement models; International Organization for Standardization, Geneva, Switzerland

59. ISO13528 (2015) Statistical methods for use in proficiency testing by interlaboratory comparison; International Organisation for Standardisation, Geneva

Publisher's Note Springer Nature remains neutral with regard to jurisdictional claims in published maps and institutional affiliations. 